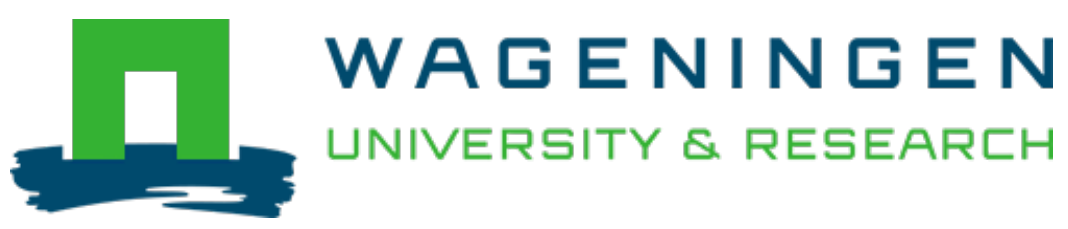

\title{
'I want to make myself useful': The value of nature-based adult day services in urban areas for people with dementia and their family carers
}

\author{
Ageing and Society \\ Bruin, Simone R.; Buist, Yvette; Hassink, Jan; Vaandrager, Lenneke \\ https://doi.org/10.1017/S0144686X19001168
}

This publication is made publicly available in the institutional repository of Wageningen University and Research, under the terms of article $25 \mathrm{fa}$ of the Dutch Copyright Act, also known as the Amendment Taverne. This has been done with explicit consent by the author.

Article 25 fa states that the author of a short scientific work funded either wholly or partially by Dutch public funds is entitled to make that work publicly available for no consideration following a reasonable period of time after the work was first published, provided that clear reference is made to the source of the first publication of the work.

This publication is distributed under The Association of Universities in the Netherlands (VSNU) 'Article $25 \mathrm{fa}$ implementation' project. In this project research outputs of researchers employed by Dutch Universities that comply with the legal requirements of Article $25 \mathrm{fa}$ of the Dutch Copyright Act are distributed online and free of cost or other barriers in institutional repositories. Research outputs are distributed six months after their first online publication in the original published version and with proper attribution to the source of the original publication.

You are permitted to download and use the publication for personal purposes. All rights remain with the author(s) and / or copyright owner(s) of this work. Any use of the publication or parts of it other than authorised under article $25 \mathrm{fa}$ of the Dutch Copyright act is prohibited. Wageningen University \& Research and the author(s) of this publication shall not be held responsible or liable for any damages resulting from your (re)use of this publication.

For questions regarding the public availability of this publication please contact openscience.library@wur.nl 


\title{
'I want to make myself useful': the value of nature-based adult day services in urban areas for people with dementia and their family carers
}

\author{
Simone R. de Bruin ${ }^{1,2 *}$ (D), Yvette Buist ${ }^{1}$, Jan Hassink ${ }^{3}$ and Lenneke Vaandrager ${ }^{2}$ \\ ${ }^{1}$ Centre for Nutrition, Prevention and Health Services, National Institute for Public Health and the \\ Environment, Bilthoven, The Netherlands, ${ }^{2}$ Department of Social Sciences, Health and Society, \\ Wageningen University \& Research, Wageningen, The Netherlands and ${ }^{3}$ Wageningen Plant Research, \\ Agrosystems Research, Wageningen University \& Research, Wageningen, The Netherlands \\ ${ }^{*}$ Corresponding author. Email: simone.de.bruin@rivm.nl
}

(Accepted 14 August 2019)

\begin{abstract}
Nature-based adult day services (ADSs) in urban areas are relatively new services in the Netherlands. Since knowledge about these services is still scarce, this study aimed to elucidate their value for people with dementia and their family carers in terms of health and wellbeing. We interviewed 39 people with dementia attending nature-based ADSs in urban areas and their family carers, and 17 providers of these services. Respondents indicated that nature-based ADSs in urban areas positively affected the health and wellbeing of people with dementia. According to them, these services support contact with nature and animals, activity engagement, physical activity, structure, social interactions, healthy eating, a sense of meaning in life and a focus on normal daily life. Respondents further indicated that these services stimulate respite, reassurance and maintenance of family carers' own activities and social contacts. We conclude that nature-based ADSs in urban areas have a wide range of benefits that might affect the health and wellbeing of people with dementia and their family carers. Worldwide, demand is growing for innovative practices in dementia care. It is therefore worthwhile monitoring the development of dementia care innovations, such as nature-based ADSs, and for countries to exchange lessons learned from these services.
\end{abstract}

Keywords: adult day services; care farm; dementia; family carers; green care; nature-based services

\section{Introduction}

The quality of long-term dementia care is widely criticised for insufficient alignment of care environments and services with the needs of people with dementia and their family carers. There is growing recognition of the need for person-centred support that goes beyond the provision of task-oriented care. Therefore, providing opportunities for meaningful occupation, social interaction and autonomy within an environment that recognises the individual's assets and needs, and within a 
culture of respect, dignity and wellbeing, is considered an important aspect of dementia care (Van Der Roest et al., 2007; Winblad et al., 2016; Morrisby et al., 2017; Forsund et al., 2018). In recent years, several innovations in long-term dementia care have been introduced in both the community and residential care. These initiatives focus on providing care in small-scale, home-like environments that integrate health and social care services with everyday life. Innovations for people with dementia living at home include Meeting Centers, community-based psychogeriatric adult day services and small-scale living facilities (Dröes et al., 2004; Ausserhofer et al., 2016; Van Haeften-van Dijk et al., 2016; Verbeek et al., 2014).

In several European countries, the Netherlands and Norway particularly, but also in countries outside Europe such as Japan and the United States of America, similar innovations emerged in the agricultural and green sectors, resulting in a wide range of nature-based services for people with dementia. These include rural farms ('green care farms'; GCFs) that combine agricultural activities with care and support services for a variety of client groups, including people with dementia. These GCFs either provide adult day services (ADSs) or 24-hour nursing care as an alternative to nursing homes. GCFs generally have some degree of farming (i.e. crops, livestock and woodland) and care (health, educational and/or social services), but the ratio between farming and care, the type of farm (e.g. dairy farm, industrial livestock farm and mixed farm) and the client groups differ. GCFs provide dementia care in a stimulating and non-institutional environment with activities, like gardening, caring for animals, walking, cooking and communal dining, centred around the normal daily lives of people with dementia and integrated in a daily routine of the farm (Pedersen et al., 2016; Anderson et al., 2017; De Boer et al., 2017; De Bruin et al., 2017; Sudmann and Borsheim, in press; Yamazaki et al., in press).

In addition to the nature-based services in rural areas, there is also an increasing number of urban-based services such as ADSs in community and institutional gardens or city farms. There is considerable variation across nature-based ADSs in urban areas in terms of initiators (e.g. health and social care professionals, social entrepreneurs, citizens), settings (e.g. city farm, community garden, garden of a long-term care institution) and client groups (e.g. people with dementia only, mixed client groups) (Hassink et al., 2016, 2019). There are different types of funding systems for nature-based ADSs including local payment schemes by municipalities for uninsurable care and support for citizens with disabilities, care innovation funds and income-related co-payments by participants (Nowak et al., 2015; Hassink et al., 2019).

Scientific evidence on the value of nature for human health and wellbeing is growing. Several interrelated mechanisms have been suggested by which nature is assumed to positively affect health and wellbeing. As suggested by Hartig et al. (2014), some mechanisms go through contact with nature (e.g. viewing, walking). Other mechanisms go through spending time in a natural environment without consciously engaging with nature as such. These mechanisms suggest that nature, through its different aspects (e.g. as physical environment, as setting for individual and social behaviour, as experience) can affect outcomes such as performance, subjective wellbeing, physiological changes and morbidity (Hartig et al., 2014; World 
Health Organization, 2017). Scientific evidence on the value of nature-based services for people with dementia is, though growing as well, still scarce. Initial studies focusing on nature-based services in rural areas, such as GCFs, suggest that these services increase engagement, physical activity, social interaction, time spent outdoors and healthy diet. These services can also promote respite, more personal time and fewer feelings of guilt among family care-givers (De Bruin et al., 2009; 2010a, 2015; De Boer et al., 2017; Sudmann and Borsheim, in press). Studies on other types of nature-based facilities, such as sensory gardens, horticultural therapy, the use of natural elements (e.g. plants) in institutional settings and local green spaces (e.g. forests), are in line with these findings and additionally suggest that these services contribute to feelings of self-worth, a sense of autonomy and identity, reduce agitation and the incidence of falls, and improve mood, quality of life and sleep (Gonzalez and Kirkevold, 2014; Whear et al., 2014; Hendriks et al., 2016; Cook, in press). Notwithstanding the fact that the findings of the different studies provided valuable insights, there are still multiple knowledge gaps regarding these facilities, particularly regarding nature-based ADSs in urban areas. As these types of services are relatively new, almost no knowledge is for instance available about the motivation of people with dementia and their family carers to avail of these services. In addition, the value of nature-based ADSs in urban areas for people with dementia and their family carers, in terms of health and wellbeing, has not yet been described.

Although nature-based ADSs in urban areas have similarities with these types of services in rural areas (e.g. in terms of activities and the focus on the outdoor life), there are some differences between both types of services that might affect the health and wellbeing of people with dementia and their family carers. Nature-based ADSs in urban areas are, for instance, offered in different types of settings (i.e. city farm, community garden, garden of long-term care institutions) than nature-based ADSs in rural areas (i.e. rural farms). Furthermore, the types of providers of nature-based ADSs in urban areas (i.e. health and social care professionals, social entrepreneurs, citizens) differ from those of nature-based ADSs in rural areas (i.e. farmers and farmers' wives). This might result in differences in dementia care approaches between both types of services. The aims of our study were therefore to: (a) understand the motivation of people with dementia and their family carers to choose nature-based ADSs in urban areas and (b) increase our understanding of the value of nature-based ADSs in urban areas in terms of the health and wellbeing of people with dementia and their family carers from different perspectives (i.e. people with dementia, family carers, providers of naturebased ADSs in urban areas).

\section{Methods}

\section{Study design and setting}

This qualitative study was performed between June and October 2017 in the Netherlands. Semi-structured interviews were conducted with people with dementia, their family carers and providers of nature-based ADSs in urban areas. In the Netherlands, five types of nature-based ADSs in urban areas can 
be distinguished: (a) social entrepreneurs offering ADS in a green environment (e.g. city farm, city garden, park); (b) nursing homes opening up their gardens to people with dementia living in the community; (c) social care organisations organising green activities (e.g. green maintenance, walks in green environments, visit to a children's farm or city farm); (d) citizens who, together with other agencies, offer nature-based ADSs in a community garden; (e) hybrid ADS type in which long-term care institutions jointly organise nature-based ADS with other types of partners (e.g. social entrepreneurs, other care institutions, citizens) (Hassink et al., 2019). A wide range of activities and jobs can be undertaken at nature-based ADSs, such as outdoor activities (e.g. sowing seeds, harvesting crops, working in the orchard, trimming hedges, sawing, taking care of animals, going for a walk, cycling), indoor or domestic activities (e.g. meal preparation, grocery shopping, laundry folding, doing the dishes) and (re-)creative activities (e.g. crafts work, playing games, making nest boxes, attending lectures about nature-related topics).

\section{Recruitment procedures}

Providers of nature-based ADSs were recruited through purposeful sampling. They were recruited by putting an invitation to participate in our study on several Dutch websites (e.g. website of a Dutch patient organisation for people with dementia, website about nature-based services) and in several newsletters on dementia care and nature-based services. They were additionally actively approached through the researchers' networks. Through these procedures, we recruited representatives of 15 nature-based ADSs, from different regions in the Netherlands, who were willing to participate in an interview for this study. Per interview, one or two people per nature-based ADS participated. In all, we interviewed 17 providers.

People with dementia (from now on called participants) and their family carers were recruited, also using purposeful sampling, via the providers of nature-based ADSs in urban areas interviewed for this study. In total, nine out of 15 providers actually recruited participants for our study. Those that did not recruit participants did not want to burden their participants or family carers. The providers gave the researchers contact details of eligible participants (i.e. people with dementia who were able to answer questions), with permission from the participants. The researchers contacted the participants and their family carers to schedule an interview. We aimed to interview approximately 30 dyads of people with dementia and their family carers. However, for logistical reasons, several people with dementia and their family carers could not be interviewed at the same time. Additionally, some family carers preferred a non-dyadic interview as they felt that they could then speak more freely or because they thought an interview would be too burdensome for their relative. For this reason, we also conducted interviews with people with dementia and family carers separately. In all, we conducted 39 interviews: 21 with participants and 18 with family carers. Ten interviews were dyad interviews of participants and their family carers, nine interviews were held with participants only, eight interviews were held with family carers only and one interview was held with two participants together. 


\section{Data collection}

Participants and their family carers were visited at their homes or at the nature-based ADS. The interviews with the providers were held at their workplace. Interviews were conducted face to face. The interviews lasted approximately 40-60 minutes and were individually conducted by five researchers from our team. To standardise the data collection procedure, four interviews with participants or their family carers were performed by pairs of researchers. In the interviews with participants, we tried to get an answer from the participants first. If they were less capable of answering our questions coherently or at all, we turned to family carers as a proxy. They either added to, or elaborated on, their relative's answers. All interviews were audiotaped with the interviewees' permission and transcribed verbatim.

The interviews with participants and family carers covered the following topics: (a) motivation to initiate nature-based ADS in an urban area; (b) value of naturebased ADS in an urban area for participants, and (c) value of nature-based ADS in an urban area for family carers. The interviews with providers covered only the second and third topics. Additionally, we collected information on sex, age, and the relationship between participants and family carers. We also collected information on the type of nature-based ADSs in urban areas and the region in which they were situated.

\section{Ethics}

Our study proposal was approved by the Social Sciences Ethics Committee of Wageningen University. The Committee concluded that our proposal dealt with ethical issues in a satisfactory way and that it complied with the Netherlands Code of Conduct for Scientific Practice. Informed consent was obtained from all respondents. A participant information sheet and consent form were developed that fully explained in lay terms the purpose of their involvement, what was expected of them, the types of questions, what would happen to their data and how their confidentiality would be maintained. The information sheets also stipulated that their involvement was voluntary and that they could choose to withdraw at any time without a reason and with no adverse effects to themselves. A signed consent form was required that verified that the participants understood their involvement and gave permission for interviews to be recorded. Signed consent was obtained before the start of the interview at the latest. For those people who were not capable of giving informed consent because of severe cognitive disorder, informed consent was requested from their family carers.

\section{Data analysis}

The framework analysis method was employed to analyse the data (Boeije, 2005; Bradley et al., 2007; Gale et al., 2013). The development of the analytical framework (i.e. the code structure) was guided by the principles of a deductive as well as an inductive approach (Bradley et al., 2007). Predetermined codes were used for the development of the initial framework. Additional codes for the analytical framework were developed by reading several interview transcripts and establishing the relevance and coherence of recurring themes. When no new themes emerged from the data, 
the analytical framework was finalised. The framework was then used by five researchers to assign codes to relevant passages of the interview transcripts (Boeije, 2005; Gale et al., 2013). The researchers checked one another's coded transcripts and discussed differences in order to reach consensus. To organise the coded transcripts and sort the data according to themes, a computer program for qualitative data analysis (i.e. MAXQDA 2018) was used. Once the interviews were coded, all coded data were examined by interpreting (recurring) items. Then drafts of the study findings were written and discussed within our team.

\section{Results}

\section{General characteristics of nature-based ADSs and respondents}

Tables 1-3 present the characteristics of providers, people with dementia and family carers that participated in our study. Different types of nature-based ADSs in urban areas were represented in this study, the majority being social entrepreneurs offering ADSs in a green environment. Four nature-based ADSs were situated in the south, five in the north and six in the middle of the Netherlands. Group sizes of the different types of nature-based ADSs ranged from three to 30 . In particular, the number of participants of nature-based ADSs provided by social entrepreneurs (type 1) varied widely. The number of people participating in naturebased ADSs provided by social care organisations (type 3$)$ was small $(\mathrm{N}=3$ participants). In addition, staff of the different types of nature-based ADSs varied widely. Staff of nature-based ADSs provided by nursing homes (type 2) and by mixtures of different agencies (type 5) were primarily health and social care professionals. Nature-based ADSs provided by social care organisations (type 3) and citizens (type 4) mainly worked with volunteers. Staff members of nature-based ADSs provided by social entrepreneurs (type 1) had more diverse backgrounds varying from health care to agriculture, landscape architecture, nature education and gardening.

The majority of people with dementia were male, with ages ranging from 51 to 90 years. Most participants attended nature-based ADSs provided by a social entrepreneur. Most of the family carers were female, with ages ranging from 46 to 82 years. Their relationship with the person with dementia was mostly partner or child.

\section{Motivation to initiate nature-based ADSs in an urban area}

This section provides insight into motivation of people with dementia and their family carers to initiate nature-based ADSs in an urban area. Important themes emerging from the interviews are presented in Table 4, and are further discussed below.

Both people with dementia and their family carers mentioned the possibility of being active and of spending time outdoors as important reasons to avail of naturebased ADSs in an urban area. Also, the green and natural environment was an important reason for them. Some people with dementia used to have a garden themselves and therefore liked being in a green environment. Other people with dementia just liked being outdoors and doing outdoor activities (e.g. going for a 
Table 1. Characteristics of providers of nature-based adult day services (ADSs) participating in this study

\begin{tabular}{|c|c|c|}
\hline Respondent & Type of nature-based $A D S^{1}$ & Region in the Netherlands \\
\hline Provider 1 & 1 & South \\
\hline Provider 2 & 3 & South \\
\hline Provider 3 & 1 & South \\
\hline Provider 4 & 5 & South \\
\hline Provider 5 & 4 & Middle \\
\hline Provider 6 & 1 & Middle \\
\hline Provider 7 & 1 & North \\
\hline Provider 8 & 5 & North \\
\hline Provider 9 & 2 & Middle \\
\hline Provider 10 & 5 & Middle \\
\hline Provider 11 & 2 & North \\
\hline Provider 12 & 1 & Middle \\
\hline Provider 13 & 1 & Middle \\
\hline Provider 14 & 2 & North \\
\hline Provider 15 & 1 & North \\
\hline
\end{tabular}

Notes: 1.1 = social entrepreneur offering ADS in a green environment (e.g. city farm, city garden, park); 2 = nursing home opening up its garden to people with dementia living in the community; $3=$ social care organisation organising green activities (e.g. green maintenance, walks in green environments, visit to a children's farm or city farm); $4=$ citizens who, together with other agencies, offer ADS in a community garden; 5 = hybrid ADS type in which a long-term care institution jointly organises nature-based ADS with other types of partners (e.g. social entrepreneur, other care institution, citizens).

walk) and activities relating to animals. People with dementia additionally mentioned that they liked to go to the ADS as that gave them the opportunity to meet people of their own age. Family carers additionally mentioned the presence of a diverse range of stimuli as an important reason to avail of ADSs in a green environment:

So, we were looking for appropriate adult day services for him, because at home, he didn't know what to do ... I then had a meeting with our case manager to discuss what kind of person he is, what kind of hobbies he has, what he likes to do. And at home, we already had a vegetable garden, and [name participant] always liked to dig in the ground, after having spent a day indoors, as a hobby really. He likes to be outdoors and active. So that's how we decided to try this [nature-based ADS in urban area], I wasn't aware of the existence of these kinds of services, but it was our case manager really that mentioned it. She said: 'Perhaps nature-based ADS at [name of the initiative] is something that he would like.' So that's how we came across this location, and from day one, he really enjoys being there. (Family carer 17)

Some people with dementia did not necessarily have an affinity with green environments and green activities. They nevertheless liked their nature-based ADS 
Table 2. Characteristics of people with dementia participating in this study

\begin{tabular}{|c|c|c|c|}
\hline Respondent & Sex & Age (years) & Type of nature-based ADS in urban area \\
\hline Participant 1 & Female & 72 & 1 \\
\hline Participant 2 & Male & 76 & 3 \\
\hline Participant 3 & Male & - & 1 \\
\hline Participant 4 & Male & - & 1 \\
\hline Participant 5 & Male & 78 & 1 \\
\hline Participant 6 & Female & 80 & 1 \\
\hline Participant 7 & Female & 90 & 1 \\
\hline Participant 8 & Male & 79 & 1 \\
\hline Participant 9 & Male & - & 1 \\
\hline Participant 10 & Male & 72 & 5 \\
\hline Participant 11 & Male & 84 & 5 \\
\hline Participant 12 & Female & 74 & 5 \\
\hline Participant 13 & Male & 81 & 1 \\
\hline Participant 14 & Male & 84 & 1 \\
\hline Participant 15 & Female & 70 & 1 \\
\hline Participant 16 & Male & 74 & 1 \\
\hline Participant 17 & Female & 51 & 1 \\
\hline Participant 18 & Female & - & 2 \\
\hline Participant 19 & Female & - & 2 \\
\hline Participant 20 & Male & 60 & 1 \\
\hline Participant 21 & Male & 67 & 1 \\
\hline
\end{tabular}

Notes: 1.1 = social entrepreneur offering adult day services (ADS) in a green environment (e.g. city farm, city garden, park); 2 = nursing home opening up its garden to people with dementia living in the community; 3 =social care organisation organising green activities (e.g. green maintenance, walks in green environments, visit to a children's farm or city farm); 4 = citizens who, together with other agencies, offer ADS in a community garden; $5=$ hybrid ADS type in which a long-term care institution jointly organises nature-based ADS with other types of partners (e.g. social entrepreneur, other care institution, citizens).

because, according to them, there was a relaxing atmosphere and staff were friendly. Other, more practical, considerations were the travel distance between a participant's home and the ADS location and whether there was a place available.

\section{Value of nature-based ADSs for people with dementia}

This section provides insight into the value of nature-based ADSs for people with dementia from different perspectives (i.e. people with dementia, family carers and providers). Important themes emerging from the interviews are presented in Table 4. Each theme is discussed below. Although they are discussed separately, it should be noted that they are interrelated and should therefore not be seen in isolation. For instance, activities were found meaningful and therefore activity engagement was generally high. 
Table 3. Characteristics of family carers participating in this study

\begin{tabular}{|c|c|c|c|}
\hline Respondent & Sex & Age (years) & Relationship with person with dementia \\
\hline Family carer 1 & Female & 49 & Daughter of participant 1 \\
\hline Family carer 2 & Female & - & Wife of participant 3 \\
\hline Family carer 3 & Female & 67 & Wife \\
\hline Family carer 4 & Female & - & Daughter of participant 5 \\
\hline Family carer 5 & Female & 52 & Daughter of participant 6 \\
\hline Family carer 6 & Female & 57 & Daughter of participant 7 \\
\hline Family carer 7 & Female & 70 & Wife \\
\hline Family carer 8 & Female & 71 & Wife of participant 8 \\
\hline Family carer 9 & Female & - & Partner of participant 9 \\
\hline Family carer 10 & Male & 67 & Brother of participant 10 \\
\hline Family carer 11 & Female & 76 & Wife of participant 11 \\
\hline Family carer 12 & Female & 75 & Wife of participant 13 \\
\hline Family carer 13 & Female & 82 & Wife of participant 14 \\
\hline Family carer 14 & Female & 59 & Ex-wife of participant 15 \\
\hline Family carer 15 & Female & 71 & Wife of participant 16 \\
\hline Family carer 16 & Male & 46 & Husband of participant 17 \\
\hline Family carer 17 & Female & 56 & Wife of participant 20 \\
\hline Family carer 18 & Female & - & Daughter of participant 21 \\
\hline
\end{tabular}

\section{Contact with nature and animals}

Being outdoors in a green environment and having contact with animals was appreciated by participants. Participants and their family carers mentioned that the ADS offered space for participants to walk, sit outside, sit in the sun and work in the garden for instance. One participant said that being outside brought back happy memories of his childhood. Also, participants stated that they were able to relax at the nature-based ADS. Some participants experienced the green environment as 'calm' and others as 'lively'. One participant said that there is space, both literally and metaphorically:

And it all feels right, because it is all very 'back to basics', with both feet on the ground. And for me that is actually quite comfortable. (Participant 20)

Family carers and participants also said that they liked to work with or watch animals such as chickens, pigs, goats and turkeys. Certain life events, such as the birth of animals, are fascinating for participants and keep them busy. According to family carers and providers, animals are 'just there', and this can put people with dementia at ease. Participants can develop close relationships with them, and for some it may be easier to bond with animals than with human beings: 
Table 4. Main themes emerging from the interviews

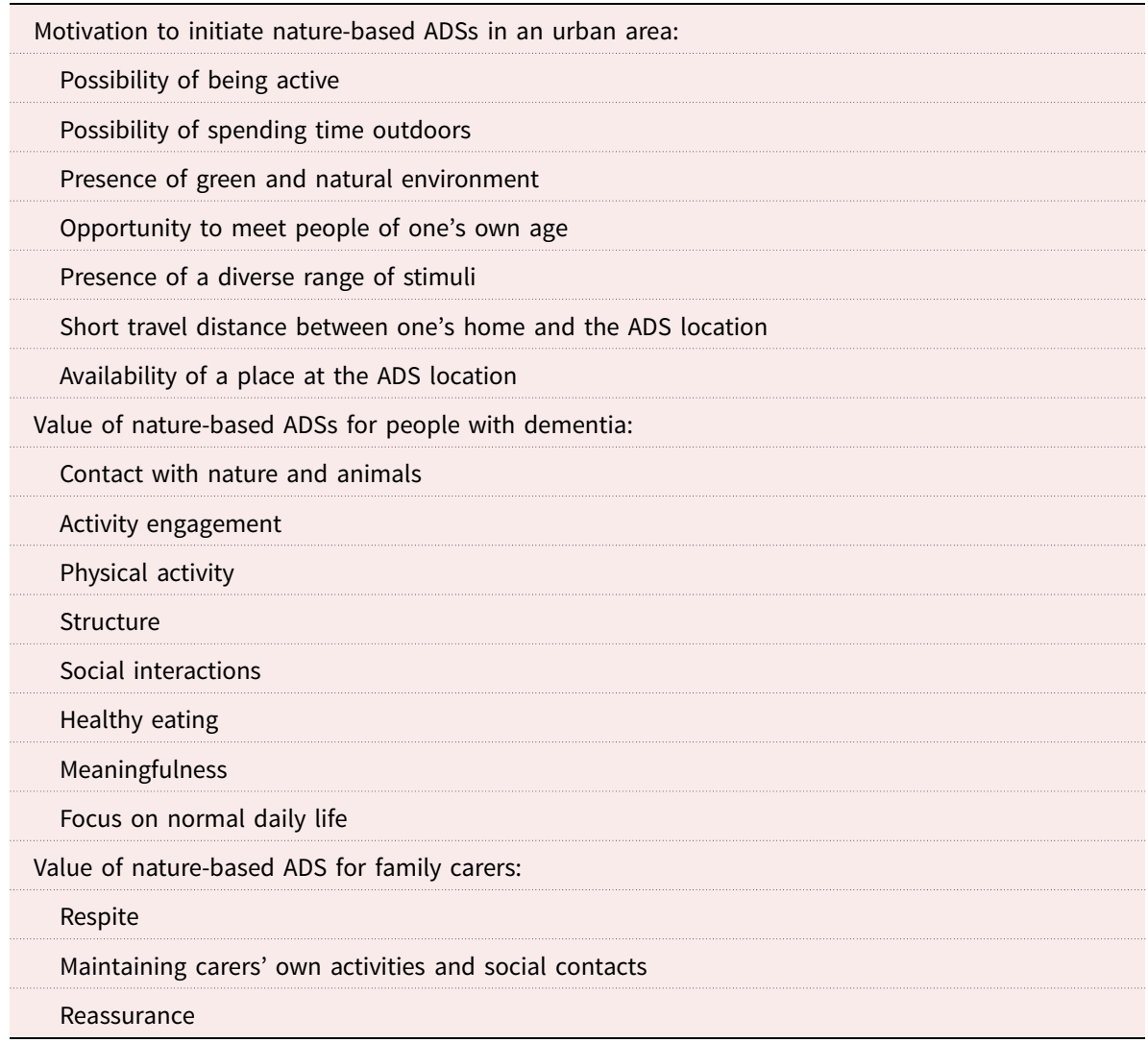

Note: ADS: adult day services.

Absolutely, yes, it is related to the fact that people can go outdoors, in the fresh air, that they are meeting animals that do not ask anything. Anything goes, it is relaxed ... Taking care of or feeding the animals, these are the kinds of skills that they do maintain. (Family carer 14)

Some family carers indicated that their relative was quite inactive at the naturebased ADS. They nevertheless thought that the ADS would positively affect their relative's health and wellbeing, because their relatives were spending time outdoors and were having joyful experiences. Participants, for instance, indicated that the ADS made them feel good. Family carers acknowledged that and additionally mentioned that the ADS made their relative feel revived and cheerful:

I always get back a very happy husband. (Family carer 15)

Additional benefits of nature-based ADS for people with dementia mentioned by providers, often attributed to time spent outdoors, were reduction of medication utilisation and a better day-night rhythm. 


\section{Activity engagement}

Participants indicated that they liked to be active and to participate in the different everyday activities and jobs they could do at the nature-based ADS. They also appreciated the fact that there was always a lot to see, such as animals, trees and plants. Some family carers were positively surprised by the kinds of activities that their relatives were still able to do:

I have one, two, three, four stables, that's what I'm starting with. These have to be tidied up and cleaned ... Then we have to remove the hay that has been spilled, or the sand if that has been used. All that has to be removed, replaced, and so on. And in the afternoon, we're having a cup of tea and a tasty lunch, and then we move on. Putting the dirty clothes in the wash, going to the goats, and so on. There's nothing left to be desired, is there? I'm really enjoying myself here. (Participant 8)

Some of the participants noted that they found it important to be active and to be stimulated to be active. At home, they would just sit on the couch and would easily fall asleep during the day. This was also mentioned by family carers. According to them, the nature-based ADS provides positive stimuli activating the brain of people with dementia, energises their relative and is a form of distraction from thinking about being ill for a while. They believed that this would positively affect the health and wellbeing of their relatives and would slow down deterioration of their functioning. Other family carers and providers said that people with dementia came home 'tired but satisfied' after they had spent a day at the ADS. They had a day full of activities and experiences and had something to tell their relatives when they came home. This was particularly appreciated by family carers, as on other days their relatives did not say and tell much. Some of the providers underlined this on the basis of the experiences shared with them by family carers. The naturebased ADS affects participants not only at the ADS, but also in their home situation:

What I often hear from relatives is that they see their partner, father or mother change to a certain extent. That someone is becoming more active, also in relation to housekeeping. So, less awaiting and passive ... And here, at work, we see of course that people are reviving because they are being activated. (Provider 15)

Here, they can expend their energy ... We have a number of relatively young men with dementia and they are coupled with someone [volunteer or professional] who is working in the garden. And then, they can really expend some of their energy. They will go home tired, and if they are able to do so, they will also have something to tell [their relatives]. (Provider 6)

Participants and family carers additionally mentioned that they appreciated participants' freedom of choice at the ADS; they can do anything they like. The fact that there are so many different possible activities and jobs facilitates engagement in an activity or job that fits participants' preferences and capacities. Staff at the ADS know what kinds of activities participants like to do and tailor their day programme accordingly. Although the different activities and jobs were highly appreciated, 
participants and family carers also mentioned valuing the fact that participants had the option to be inactive and to do nothing at all. As one of the family carers put it:

Within the possibilities, everyone is being motivated to function at his or her own level. What I also really like is that anything goes ... If you don't want it, no problem at all. (Family carer 5)

Well, that you can just go to the garden if you don't feel like doing anything anymore. That's fine as well. That you can just stop ... anything goes. The freedom actually. (Participant 12)

\section{Physical activity}

Another benefit of nature-based ADSs mentioned by all three types of respondents was physical activity. The different types of activities and jobs, as well as the outdoor environment with different places to go to (e.g. garden, stable, orchard, work shed), stimulate people with dementia to be physically active. Several participants indicated enjoying being physically active, for instance by shovelling or raking. Family carers also were pleased that their relatives were, at least some days of the week, physically active:

[Name of participant] is actually very sporty but he also likes to read or to stare out of the window. However, I think, because he is active on Mondays and Fridays [at the nature-based ADS], that he is also more active on the other week days. And should he be inactive on Tuesdays and Wednesdays, that wouldn't matter; at least he was active on Mondays and Fridays. (Family carer 9)

\section{Structure}

According to family carers, the nature-based ADS provided structure for their relatives. Participants are, for instance, often picked up at their homes around the same time. At the ADS, there is mostly a fixed day structure, with dedicated times for activities and jobs, coffee and tea, and lunch. Every day, there are activities that need to be done, such as caring for animals, harvesting crops for lunch, preparing vegetables for lunch, and so on. The seasons play a role in offering a certain structure, for instance animals are born, animals grow up, seeds need to be sown, crops need to be harvested.

.... and the seasons, of course, you experience a lot more ... Whereas, when you are sitting inside [institutional ADS], everything is always more or less the same. (Family carer 16)

\section{Social interactions}

The interviews with all three types of respondent revealed that nature-based ADSs facilitated social interactions. Three types of social interaction were mentioned: interaction with other participants, with other visitors (e.g. general public, children) to the nature-based ADS and with staff.

Participants mentioned that they liked to meet other people and that it was easy to get to know one another. For some participants, the social interactions were 
considered the most valued aspect of the ADS. Some participants mentioned that they had to get used to all those new faces or that they could not get along with everyone, but there were sufficient other people to connect with. Family carers also were happy that their relatives were meeting new people. There were mutual connections between participants, and some participants stated that there was a lot of chatting (e.g. about daytime activities), teasing and joking, as, for instance, illustrated by one participant and carer:

No, but I'm really enjoying it, so it's fine as it is. One gets to know one another in this way as well ... we are continuously having fun. (Participant 16)

And if there is a barbecue or at Christmas, then everyone is there too and then I see that everyone is very friendly to him ... Yeah, the place has a good atmosphere. Also [name of one of the staff members] says: 'we have very nice people here'. Yeah, I am really a great fan of them. It's a nice place to stay. (Family carer 2)

Participants, family carers and providers all mentioned interactions with other kinds of visitors. Some ADSs were visited by children from nearby schools, which was also appreciated by the participants, as a family carer illustrated:

....and the small children that are sometimes around. Nursery classes, for instance, that are visiting the ADS. Well, he loves that. These are the things that he still knows when he is coming home at night. (Family carer 7)

Some nature-based ADSs had a shop, a restaurant, or freely distributed fruits and vegetables to people in the community, and this resulted in different kinds of people visiting the ADS. Family carers and providers found this beneficial for people with dementia. According to them, the ADS enabled people with dementia to remain part of society and stimulated a sense of belonging:

...Other visitors, from the community, visit this place [nature-based ADS] as well, so this is some sort of miniature society, a faithful reflection of society. This is what I think is the value, that we are not only a group of people with dementia, but that there are all kinds of people here. (Provider 3)

Interactions with staff members of the nature-based ADS were appreciated as well. Several participants indicated that they connected well with the staff and that staff members were enthusiastic about them. According to them, staff members facilitated and contributed to social interactions with and between participants. Participants and their family carers noted that staff members were taking good care of them and were treating them with dignity. They further mentioned that staff members listened carefully to people with dementia, respected their preferences and capacities, and were interested in both the person with dementia and his or her family carer. Some family carers found it special that staff members, as well as volunteers working at the nature-based ADS, paid so much attention to their relative. They found staff members personally involved and passionate 
about their job. They also noticed that there were always volunteers around to interact with, and organise activities for, the participants:

What I find is that people are working with passion here. The professionals, and also the volunteers, have consciously decided to work with people with dementia. That's what you see in their approach; they are always calm, friendly ... And also the passion, also my husband said so, they deal passionately with everything and talk about the people here. Yes, that is really special. (Family carer 5)

In holiday seasons, there were generally regular changes in staff. This was something that family carers perceived as less positive.

\section{Healthy eating}

At most nature-based ADSs, a communal meal prepared and consumed around lunchtime is seen as a main component of the day. According to family carers and providers, communal dining not only stimulates social interactions between participants, but also seems to stimulate healthy eating. As a family carer put it:

It was very difficult for her to regain weight. And then she started at the farm ... And since then, we noticed that she gained weight, had more appetite, started to eat better. It has absolutely to do with the fact that people can go outdoors there, in the fresh air. (Family carer 14)

\section{Meaningfulness}

Participants said that they liked to do something meaningful; this was also acknowledged by their family carers and providers. Especially the relatively younger participants said that they found it important and satisfying to do meaningful work. As several respondents put it:

And here I am, in my boots, doing outdoor work, like a kind of farmer, or well, whatever ... with a shovel and a spade. And at the end of the day, when I am going home, I'm feeling really great. (Participant 20)

Yes, I want to make myself useful. Physically, I can still do a lot. My mind may not be quite there, but my body can still handle a lot. (Participant 1)

So, we just see that he is feeling better, he is meaningful again, he means something to people. A sense of meaningfulness is very important for people with this condition. You just see that he revives whenever he goes there. (Family carer 4)

Yes, after some time, though not from everyone, we hear that they really like being here. They are enjoying themselves and they are feeling themselves useful. (Provider 10)

Participants with knowledge of gardening noted that they were happy to use and share their knowledge and thus to mean something to others. Some participants perceived being at the nature-based ADS as having paid employment. This was 
also mentioned by some of the family carers and providers. A family carer explained from her perspective:

Because the feeling that they need them ... because he thinks that he is going to work ... And you know, if you feel useless that is not good for someone. Everyone wants to be useful, don't you think? No matter how. (Family carer 3)

\section{Focus on normal daily life}

Providers mentioned that an important benefit of a nature-based ADS is that it is just a normal, non-institutional kind of place. According to them, there is no stigmatising; there is a sense of belonging and everyone is equal. They further mentioned finding it important that people with dementia, but also their family carers, can participate in society for as long as possible:

So that people come into their own, that they have social contacts, that you sometimes cannot see if somebody has dementia or not ... And that a visitor who comes to have a look thinks 'Who is the person who is needing care and who is not?' So, the difference falls away. That is very pleasant for some people. (Provider 7)

\section{Value of nature-based ADS for family carers}

This section provides insight into the value of nature-based ADSs for family carers from the perspectives of family carers and providers. Important themes emerging from the interviews are summarised in Table 4. Each theme is discussed below.

\section{Respite}

Both family carers and providers indicated that family carers could unwind on the days their relatives were at the nature-based ADS. On these days, they did not have to take care of their relative or to worry about their relative for a day:

For myself, that I can catch my breath. Because I notice that it is getting heavier. (Family carer 3 )

\section{Maintaining carers' own activities and social contacts}

Family carers and providers noted that nature-based ADSs ensured that family carers had time for doing their own activities (e.g. work, grocery shopping, housekeeping, bookkeeping) and meeting with family and friends. Some family carers indicated that, because their relative was attending an ADS, they were able to have a relatively normal living and working pattern.

\section{Reassurance}

A final benefit of nature-based ADSs, again mentioned by both family carers and providers, was reassurance. For instance, for them it was a reassuring and pleasant thought that their relative was at the right place, which he or she liked to visit. Therefore, family carers did not feel guilty about shifting responsibilities for their relative to an ADS for some days a week. As a family carer and provider put it: 
So, I am very happy that it [nature-based ADS] is there, which I have already said, because I leave him here with peace of mind, knowing that he is well taken care of and that there is structure. And above all that he enjoys it. (Family carer 4)

...that you know that your partner is going somewhere where he will enjoy himself, that he is in a pleasant and stimulating environment. I think it will be easier for family carers then to let go. Because that's what it is all about, isn't it? It is not only about 'parking' someone at an ADS, having one's hands free and settling down. (Provider 6)

Reassurance was also derived from the support some family carers received from professionals from the nature-based ADS. In some cases, this was practical support, but emotional support, involvement in activities at the ADS, and talking about the health and wellbeing of their relative were also mentioned. This made family carers feel less alone in caring for their relative.

\section{Discussion}

This study explored the motivation of people with dementia and their family carers to choose a nature-based ADS in an urban area and the value of this type of ADS for people with dementia and their family carers in terms of health and wellbeing from different perspectives. This study suggests that, for people with dementia and their family carers, choosing a nature-based ADS in an urban area, the characteristics of the person with dementia (i.e. affinity with outdoor life, love for animals) and the characteristics of the nature-based ADS (i.e. opportunities to be active and outdoors, presence of gardens, presence of animals) played an important role in the selection of the ADS setting. This is very much in line with the findings of earlier studies (De Bruin et al., 2015; De Boer, 2017) on nature-based ADSs in rural areas, where similar considerations were observed, and where, for people who chose an institution-based ADS, the selection of that ADS setting seemed to be less deliberate and more pragmatic (e.g. following advice of the care professional who was managing the process, the institutionbased ADS was nearby, a nature-based ADS was not nearby). In the current study, we also observed some more practical considerations (e.g. travel distance between home and the ADS location and the availability of a place at the ADS), but these were less pronounced in our findings.

This study further reveals that several benefits for people with dementia and their family carers were attributed to nature-based ADSs in urban areas. These benefits were mentioned by all three types of respondents (i.e. participants, family carers, providers). Although we interviewed people with dementia and their family carers of different sexes and ages, and providers from different types of nature-based ADSs, there were no clear differences in the benefits mentioned. Respondents indicated that nature-based ADSs in urban areas positively affect the health and wellbeing of people with dementia and their family carers. According to them, these services support contact with nature and animals, activity engagement, physical activity, structure, social interactions, healthy eating, a sense of meaning in life and a focus on normal daily life. Respondents further indicated 
that nature-based ADSs stimulate respite, maintenance of carers' own activities and social contacts, and reassurance of family carers.

From this this study, we can conclude that nature-based ADSs in urban areas and nature-based ADSs in rural areas have similar benefits in terms of health and wellbeing (De Bruin et al., 2009, 2010a, 2015, 2017; De Boer et al., 2017; Sudmann and Borsheim, in press). It should further be noted that participants and family carers generally had positive experiences with the nature-based ADSs, for instance in terms of possible activities and jobs, environmental characteristics, staff members and other participants. Only a few less-positive experiences were mentioned, for instance dislike of a particular participant or too many staff changes in holiday seasons.

It should further be noted that, as in earlier studies on nature-based services in rural areas (De Bruin et al., 2009, 2010a, 2015), we observed that the majority of the users of nature-based ADSs in urban areas described in this paper were males. In line with the study of Manthorpe and Moriarty (2014), our study suggests that males prefer activities that seem to be useful and support their identity. Males seem to be less inclined to attend day services in a traditional ADS setting because these services match their preferences and competences less well.

Our findings are important in view of ongoing discussions about improving the quality of dementia care and recognising the individual's assets and needs. Previous studies suggest that the needs of people with dementia are often insufficiently met in dementia care (Cohen-Mansfeld et al., 2015; Den Ouden et al., 2015; Morrisby et al., 2017; Forsund et al., 2018). Prevalent unmet needs of people with dementia include, for instance, social interaction, meaningful activity, autonomy, sensory stimulation and enjoyment. The various studies therefore underline the importance of tailoring and personalising care to the needs of people with dementia. The needs of family carers are also often insufficiently addressed (Morrisby et al., 2017; Tatangelo et al., 2018). Family carers, for instance, find that peer support and emotional support are lacking. They also find it important to discuss challenges in caregiving, to have personal time and to have time away from their care-giving role. The current study suggests that nature-based ADSs in urban areas address participants' preferences and needs, and align their care services with these needs and preferences as much as possible. In turn, this may result in improved outcomes in people with dementia, e.g. in terms of behavioural symptoms, cognition, physical functioning, quality of life, sense of purpose and wellbeing (Day et al., 2000; Smit et al., 2012, Clark et al., 2013; Anderiesen et al., 2014; Whear et al., 2014; Milke et al., 2015; Fleming et al., 2016; Kok et al., 2016).

It should be noted that other types of ADSs are also able to address several of the preferences and needs of people with dementia, such as maintaining social interactions, participation and enjoyment of activities, and connections with staff (Dabelko-Schoeny and King, 2010; Fields et al., 2014; De Bruin et al., 2015). However, nature-based ADSs seem very well able to integrate several important aspects of dementia care (e.g. natural elements, freedom of choice, autonomy, social interactions, outdoor spaces, animals, meaningful activities, person-centred approach of staff) (De Bruin et al., 2017; Buist et al., 2018). Thus, they seem to acknowledge the importance of addressing not only the physical and social environment but also the 'lived space' of people with dementia in which a sense 
of belonging, meaningfulness, security and autonomy are essential elements (Forsund et al., 2018).

It should further be noted that some prevalent needs of family carers are also being addressed by nature-based ADSs in urban areas. In the present study, family carers, for instance, felt that they received support from staff members, regained some time for themselves and could share their care-giving role. Although these findings are relevant, it should at the same time be acknowledged that these benefits may not be unique to nature-based ADSs in urban areas. Other types of services, such as so-called Meeting Centers and institution-based ADSs (Dröes et al., 2006, 2017; Fields et al., 2014; Tretteteig et al., 2017a, 2017b), seem to fulfil these types of needs as well.

\section{Methodological considerations}

For this study, we interviewed people with dementia and family carers from nine nature-based ADSs and providers from 15 nature-based ADSs. From a related study (Hassink et al., 2019), we know that there is much heterogeneity among nature-based ADSs in urban areas in terms of, for instance, initiators and settings. Although this study provided valuable insights, most participants attended naturebased ADSs offered by social entrepreneurs. Thus, insights into differences between the different types of services in terms of experiences and benefits for people with dementia and their family carers are still lacking. We tried to include people with dementia and family carers from different types of nature-based ADSs, but ADSs offered by social entrepreneurs are the most common in the Netherlands. Most of the providers that we interviewed were social entrepreneurs as well. We may therefore have introduced some bias. Social entrepreneurs are expected to be innovators and early adopters of the nature-based ADS concept. They will probably believe strongly in the concept and will also be very dependent on income from their service. Social entrepreneurs will therefore benefit from positive views on the value of nature-based ADSs and may therefore have more positive views than other types of nature-based ADSs.

Another methodological issue that should be addressed is that people with dementia and their family carers were recruited via providers of nature-based ADSs. This approach may potentially have caused selection bias, although providers were requested to ask any participant or family carer. As a result, our sample may include, for instance, particularly participants and family carers that were very positive about nature-based ADSs. Nevertheless, during the interviews, the interviewers stimulated respondents to share any less-positive experiences as well, and asked them what they did not like or what they thought could be improved. Therefore, we believe that we have obtained a reliable insight into experiences with nature-based ADSs in urban areas.

In this study, we interviewed people with dementia knowing that interviewing these people can be challenging, particularly for those people with reduced oral communication capacities. In those cases, other methods, such as photovoice (Wiersma, 2011; Evans et al., 2016), could have been a more appropriate method to capture their experiences and views. Nevertheless, different strategies were in place to obtain rich interview data. Most interviews with participants, for instance, 
took place at the nature-based ADSs. This was done to support and stimulate them to talk about their experiences with these ADSs. In those interviews conducted at the participants' homes, and where a family carer was also present, family carers were asked to either add to, or elaborate on, the answers given by their relatives.

\section{Conclusions}

Much of the research undertaken on nature-based ADSs for people with dementia originates from the Netherlands, Norway and the United Kingdom (GarciaLlorente et al., 2018; Moeller et al., 2018). This might be explained by the fact that, in these countries, several innovative dementia care concepts have been implemented. The level of implementation of dementia care innovations, such as naturebased services, differs widely across countries. Nevertheless, worldwide, there is a growing demand for innovative practices for people with dementia and a different approach to dementia. According to, for instance, Droës et al. (2016), the social consequences of dementia should receive at least as much attention as the cognitive consequences. Moreover, worldwide it is increasingly being recognised that the natural environment can provide several therapeutic benefits to people with dementia. Nature is an abundant source of multi-sensory stimulation, e.g. through light, odours, sound, touch and tastes. Nature can also evoke memories and help to retain links with reality, for instance with activities and events related to seasons (Chalfont, 2008; De Bruin et al., 2010b; Gonzalez and Kirkevold, 2014; Whear et al., 2014; Hendriks et al., 2016). It is therefore recommended that the development of dementia care innovations, including nature-based ADSs and other naturebased services, should be monitored, and that countries should exchange lessons learned from these services. Scientific and practical knowledge (e.g. solutions to potential barriers) will be valuable to policy makers and care providers for designing, delivering and including nature-based services in dementia care in their countries.

Nature-based services, such as the ADSs in urban areas described in this paper, are still a relatively new phenomenon on the dementia care pathway. Although scientific evidence on the value of nature-based services for people with dementia is gradually growing, there are still several knowledge gaps that need to be addressed. This paper, for instance, created a positive image of nature-based ADSs in urban areas. This is probably mainly because we particularly interviewed respondents with positive experiences and views on these types of services. However, this study did not provide insight into those respondents who did not want to attend a nature-based ADS or who dropped out because of less-positive experiences. It would be worthwhile exploring the less-positive views to be able to identify starting points to potentially improve the quality of these services. Another area that might benefit from further research is why nature-based ADSs in urban areas are particularly offered by social entrepreneurs. Many long-term care institutions have a garden or access to green environments in their surroundings. However, they experience several barriers to actively incorporating these environments in their services. These are related to the physical environment in which the care institutions are situated (e.g. the degree of urbanisation), characteristics of people with dementia (e.g. the stage of the disease), attitudes and competences of 
staff members (e.g. flexibility, creativity), attitudes and competences of managers (e.g. leadership, vision, support to go outdoors) and the political context (e.g. application of risk and safety protocols) (Gonzalez and Kirkevold, 2014; Buist et al., 2018). It would be worthwhile investigating what steps would be necessary to remove these barriers. Furthermore, it would be of interest to investigate the longterm impact of attending a nature-based ADS in an urban area. The current study provided first insights into the potential benefits in terms of health and wellbeing. However, we do not yet know whether, for instance, the healthy eating will actually lead to an improved nutritional status. Nor do we know what the impact of enhanced physical activity will be. The answers to these questions would help to elucidate the long-term impact of these services on the health and wellbeing of people with dementia.

From this study, we conclude that nature-based ADSs in urban areas have a wide range of benefits that might affect the health and wellbeing of people with dementia and their family carers. Worldwide, there is a growing demand for innovative practices in dementia care. It is, therefore, worthwhile monitoring the development of dementia care innovations, such as nature-based ADSs, and countries exchanging lessons learned from these services. This will ultimately support the development and implementation of high-quality dementia care services, enhancing the health and wellbeing of people with dementia and their family carers.

Acknowledgements. This paper was made possible by the contributions of people with dementia, their family carers and providers of nature-based adult day services in urban areas. The authors thank them for sharing their experiences with us. The authors additionally thank Mirte Lindhout and Marion Hoogeveen for their contributions to data collection. Finally, the authors would like to thank the members of the advisory board set up for this project who reflected critically on the outcomes of our study.

Author contributions. SB designed the study, contributed to data analysis and wrote the paper. $\mathrm{YB}, \mathrm{JH}$ and LV designed the study, collected and analysed the data, and contributed to the paper. All authors read and approved the final version of the paper.

Financial support. This work was supported by the Netherlands Organization for Health Research and Development (grant number 70-73305-98-613) and the Dutch Alzheimer's Association. They played no role in the design and execution of the study, the data analysis or writing of the paper.

Conflict of interest. The authors declare no conflicts of interest.

Ethical standards. The study proposal was approved by the Social Sciences Ethics Committee of Wageningen University.

\section{References}

Anderiesen H, Scherder EJ, Goossens RH and Sonneveld MH (2014) A systematic review - physical activity in dementia: the influence of the nursing home environment. Applied Ergonomics 45, 16781686.

Anderson KA, Chapin KP, Reimer Z and Siffri G (2017) On fertile ground: an initial evaluation of green care farms in the United States. Home Health Care Services Quarterly 36, 1-15.

Ausserhofer D, Deschodt M, De Geest S, van Achterberg T, Meyer G, Verbeek H, Sjetne IS, Malinowska-Lipien I, Griffiths P, Schluter W, Ellen M and Engberg S (2016) 'There's no place like home': a scoping review on the impact of homelike residential care models on resident-, family-, and staff-related outcomes. Journal of the American Medical Directors Association 17, 685-693.

Boeije H (2005) Analysing in Qualitative Research. The Hague: Boom Lemma. (in Dutch) 
Bradley E, Curry L and Devers K (2007) Qualitative data analysis for health services research: developing taxonomy, themes, and theory. Health Services Research 42, 1758-1772.

Buist Y, Verbeek H, de Boer B and de Bruin SR (2018) Innovating dementia care; implementing characteristics of green care farms in other long-term care settings. International Psychogeriatrics 30, 1057-1068.

Chalfont G (2008) Design for Nature in Dementia Care. London: Jessica Kingsley Publishers.

Clark P, Mapes N, Burt J and Preston S (2013) Greening Dementia - A Literature Review of the Benefits and Barriers Facing Individuals Living with Dementia in Accessing the Natural Environment and Local Green Space (Natural England Commissioned Report No. 137). Worcester, UK: Natural England and Other Parties.

Cohen-Mansfeld J, Dakheel-Ali M, Marx MS, Thein K and Regier NG (2015) Which unmet needs contribute to behaviour problems in persons with advanced dementia. Psychiatry Research 228, 59-64.

Cook M (in press) Using urban woodlands and forests as places for improving the mental well-being of people with dementia. Leisure Studies. Available online doi:10.1080/02614367.2019.1595091.

Dabelko-Schoeny H and King S (2010) In their own words: participants' perceptions of the impact of adult day services. Journal of Gerontological Social Work 53, 176-192.

Day K, Carreon D and Stump C (2000) The therapeutic design of environments for people with dementia: a review of the empirical research. The Gerontologist 40, 397-416.

De Boer B (2017) Living at a Green Care Farm: An Innovative Alternative for Regular Care in Nursing Homes for People with Dementia (PhD thesis). CAPHRI Care and Public Health Research Institute, Department of Health Services Research, Maastricht University, Maastricht, The Netherlands.

De Boer B, Hamers JP, Zwakhalen SM, Tan FE, Beerens HC and Verbeek H (2017) Green care farms as innovative nursing homes, promoting activities and social interaction for people with dementia. Journal of the American Medical Directors Association 18, 40-46.

De Bruin SR, De Boer B, Beerens H, Buist Y and Verbeek H (2017) Rethinking dementia care: the value of green care farming. Journal of the American Medical Directors Association 18, 200-203.

De Bruin SR, Oosting SJ, Kuin Y, Hoefnagels ECM, Blauw YH, De Groot CPGM and Schols JMGA (2009) Green care farms promote activity among elderly people with dementia. Journal of Housing for the Elderly 23, 368-389.

De Bruin SR, Oosting SJ, Tobi H, Blauw YH, Schols JMGA and De Groot CPGM (2010a) Day care at green care farms: a novel way to stimulate dietary intake of community-dwelling older people with dementia? Journal of Nutrition, Health \& Aging 14, 352-357.

De Bruin SR, Oosting SJ, van der Zijpp AJ, Enders-Slegers MJ and Schols JMGA (2010b) The concept of green care farms for older people with dementia: an integrative framework. Dementia 9, 79-128.

De Bruin SR, Stoop A, Molema CCM, Vaandrager L, Hop P and Baan CA (2015) Green care farms: an innovative type of adult day service to stimulate social participation of people with dementia. Gerontology and Geriatric Medicine 1-10. https://doi.org/10.1177/2333721415607833.

Den Ouden M, Bleijlevens MH, Meijers JM, Zwakhalen SM, Braun SM, Tan FE and Hamers JP (2015) Daily (in)activities of nursing home residents in their wards: an observation study. Journal of the American Medical Directors Association 16, 963-968.

Dröes R, Chattat R, Diaz A, Gove D, Graff M, Murphy K, Verbeek H, Vernooij-Dassen M, Clare L and Johannessen A (2016) Social health and dementia: a European consensus on the operationalization of the concept and directions for research and practice. Aging \& Mental Health 1-14.

Dröes RM, Meiland FJM, Evans S, Brooker D, Farina E, Szcześniak D, Van Mierlo LD, Orrell M, Rymaszewska J and Chattat R (2017) Comparison of the adaptive implementation and evaluation of the Meeting Centers Support Program for people with dementia and their family carers in Europe; study protocol of the MEETINGDEM project. BMC Geriatrics 17.

Dröes RM, Meiland F, Schmitz M and van Tilburg W (2004) Effect of combined support for people with dementia and carers versus regular day care on behaviour and mood of persons with dementia: results from a multi-centre implementation study. International Journal of Geriatric Psychiatry 19, 673-684.

Dröes RM, Meiland FJM, Schmitz MJ and Van Tilburg W (2006) Effect of the Meeting Centres Support Program on informal carers of people with dementia: results from a multi-centre study. Aging \& Mental Health 10, 112-124.

Evans D, Robertson J and Candy A (2016) Use of photovoice with people with younger onset dementia. Dementia (London) 15, 798-813. 
Fields NL, Anderson KA and Dabelko-Schoeny H (2014) The effectiveness of adult day services for older adults: a review of the literature from 2000 to 2011. Journal of Applied Gerontology 33, 130-163.

Fleming R, Goodenough B, Low LF, Chenoweth L and Brodaty H (2016) The relationship between the quality of the built environment and the quality of life of people with dementia in residential care. Dementia 15, 663-680.

Forsund LH, Grov EK, Helvik AS, Juvet LK, Skovdahl K and Eriksen S (2018) The experience of lived space in persons with dementia: a systematic meta-synthesis. BMC Geriatrics 18, 33.

Gale NK, Heath G, Cameron E, Rashid S and Redwood S (2013) Using the framework method for the analysis of qualitative data in multi-disciplinary health research. BMC Medical Research Methodology 13, 117.

Garcia-Llorente M, Rubio-Olivar R and Gutierrez-Briceno I (2018) Farming for life quality and sustainability: a literature review of green care research trends in Europe. International Journal of Environmental Research in Public Health 15, doi: 10.3390/ijerph15061282.

Gonzalez MT and Kirkevold M (2014) Benefits of sensory garden and horticultural activities in dementia care: a modified scoping review. Journal of Clinical Nursing 23, 2698-2715.

Hartig T, Mitchell R, De Vries S and Frumkin H (2014) Nature and health. Annual Review of Public Health 35, 207-228.

Hassink J, Salverda I, Vaandrager L, Van Dam R and Wentink C (2016) Relationships between green urban citizens' initiatives and local governments. Cogent Social Sciences 2, 1250336. http://dx.doi.org/ 10.1080/23311886.2016.1250336.

Hassink J, Vaandrager L, Buist Y and De Bruin SR (2019) Characteristics and challenges for the development of nature-based adult day services in urban areas for people with dementia and their family caregivers. International Journal of Environmental Research and Public Health 16, 1337.

Hendriks IH, van Vliet D, Gerritsen DL and Dröes R-M (2016) Nature and dementia: development of a person-centered approach. International Psychogeriatrics 28, 1455-1470.

Kok JS, van Heuvelen MJ, Berg IJ and Scherder EJ (2016) Small scale homelike special care units and traditional special care units: effects on cognition in dementia; a longitudinal controlled intervention study. BMC Geriatrics 16, 47.

Manthorpe J and Moriarty J (2014) Examining day centre provision for older people in the UK using the Equality Act 2010: findings of a scoping review. Health and Social Care in the Community 22, 352-360.

Milke DL, Leask J, George C and Ziolkowski S (2015) Eight years of data on residents in small dementiacare settings suggest functional performance is maintained. Journal of Housing for the Elderly 29, 298-328.

Moeller C, King N, Burr V, Gibbs GR and Gomersall T (2018) Nature-based interventions in institutional and organisational settings: a scoping review. International Journal of Environmental Health Research 28, 293-305.

Morrisby C, Joosten A and Ciccarelli M (2017) Do services meet the needs of people with dementia and carers living in the community? A scoping review of the international literature. International Psychogeriatrics 1-10.

Nowak SJM, Molema CCM, Baan CA, Oosting SJ, Vaandrager L, Hop P and De Bruin SR (2015) Decentralisation of long-term care in the Netherlands: the case of day care at green care farms for people with dementia. Ageing \& Society 35, 704-724.

Pedersen I, Patil G, Berget B, Ihlebæk C and Gonzalez MT (2016) Mental health rehabilitation in a care farm context: a descriptive review of Norwegian intervention studies. Work 53, 31-43.

Smit D, de Lange J, Willemse B and Pot AM (2012) The relationship between small-scale care and activity involvement of residents with dementia. International Psychogeriatrics 24, 722-732.

Sudmann TT and Borsheim IT (in press) 'It's good to be useful': activity provision on green care farms in Norway for people living with dementia. International Practice Development Journal. Available online doi.org/10.19043/ipdj.7SP.008.

Tatangelo G, McCabe M, Macleod A and You E (2018) 'I just don't focus on my needs.' The unmet health needs of partner and offspring caregivers of people with dementia: a qualitative study. International Journal of Nursing Studies 77, 8-14.

Tretteteig S, Vatne S and Rokstad AMM (2017a) The influence of day care centres designed for people with dementia on family caregivers - a qualitative study. BMC Geriatrics 17, 5.

Tretteteig S, Vatne S and Rokstad AMM (2017b) Meaning in family caregiving for people with dementia: a narrative study about relationships, values, and motivation, and how day care influences these factors. Journal of Multidisciplinary Healthcare 10, 445. 
Van Der Roest HG, Meiland FJM, Maroccini R, Comijs HC, Jonker C and Dröes RM (2007) Subjective needs of people with dementia: a review of the literature. International Psychogeriatrics 19, 559-592.

Van Haeften-van Dijk AM, Meiland FJ, Hattink BJ, Bakker TJ and Droes RM (2016) Community day care with carer support versus usual nursing home-based day care: effects on needs, behavior, mood, and quality of life of people with dementia. International Psychogeriatrics 28, 631-645.

Verbeek H, Zwakhalen SMG, Van Rossum E, Ambergen T, Kempen GIJM and Hamers JPH (2014) Effects of small-scale, home-like facilities in dementia care on residents' behavior, and use of physical restraints and psychotropic drugs: a quasi-experimental study. International Psychogeriatrics 26, 657-668.

Whear R, Coon JT, Bethel A, Abbott R, Stein K and Garside R (2014) What is the impact of using outdoor spaces such as gardens on the physical and mental well-being of those with dementia? A systematic review of quantitative and qualitative evidence. Journal of the American Medical Directors Association 15, 697-705.

Wiersma EC (2011) Using photovoice with people with early-stage Alzheimer's disease: a discussion of methodology. Dementia 10, 203-216.

Winblad B, Amouyel P, Andrieu S, Ballard C, Brayne C, Brodaty H, Cedazo-Minguez A, Dubois B, Edvardsson D, Feldman H, Fratiglioni L, Frisoni GB, Gauthier S, Georges J, Graff C, Iqbal K, Jessen F, Johansson G, Jonsson L, Kivipelto M, Knapp M, Mangialasche F, Melis R, Nordberg A, Rikkert MO, Qiu C, Sakmar TP, Scheltens P, Schneider LS, Sperling R, Tjernberg LO, Waldemar G, Wimo A and Zetterberg H (2016) Defeating Alzheimer's disease and other dementias: a priority for European science and society. Lancet Neurology 15, 455-532.

World Health Organization (2017) Urban Green Space Interventions and Health: A Review of Impacts and Effectiveness. Copenhagen: World Health Organization Europe.

Yamazaki S, Ura C, Okamura T, Shimmei M, Ishiguro T, Torishima $\mathrm{K}$ and Kawamuro $\mathrm{Y}$ (in press) Long-term effects of rice-farming care on cognitive function and mental health of elderly people with cognitive impairment: a follow-up study. Psychogeriatrics. Available online.

Cite this article: de Bruin SR, Buist Y, Hassink J, Vaandrager L (2019). 'I want to make myself useful': the value of nature-based adult day services in urban areas for people with dementia and their family carers. Ageing \& Society 1-23. https://doi.org/10.1017/S0144686X19001168 